\title{
Cellular viability and osteogenic differentiation potential of human gingiva-derived stem cells in 2D culture following treatment with anionic, cationic, and neutral liposomes containing doxorubicin
}

\author{
HYUNJIN LEE ${ }^{1 *}$, JIHWAN SON $^{2 *}$, GAWON YI $^{2}$, HEEBEOM KOO $^{2}$ and JUN-BEOM PARK ${ }^{1}$ \\ Departments of ${ }^{1}$ Periodontics and ${ }^{2}$ Medical Lifescience, College of Medicine, \\ The Catholic University of Korea, Seoul 06591, Republic of Korea
}

Received October 21, 2017; Accepted August 16, 2018

DOI: $10.3892 /$ etm.2018.6777

\begin{abstract}
The effects of doxorubicin, particularly doxorubicin liposome, on stem cells have remained to be fully elucidated. The aim of the present study was to evaluate the effects of anionic, cationic and neutral liposomes loaded with doxorubicin on the viability and osteogenic differentiation potential of human gingiva-derived stem cells in two-dimensional culture. Doxorubicin-loaded liposomes were prepared using the traditional thin-lipid-film hydration method. Stem cells were seeded on a culture plate and maintained in osteogenic media. The morphology of the stem cells was observed under an inverted microscope. The number of viable cells was determined using a Cell-Counting Kit- 8 assay. The alkaline phosphatase activity was assessed and Alizarin Red S staining was performed to evaluate osteogenic differentiation. A higher concentration of doxorubicin caused noticeable changes in the morphology of the stem cells. Decreases in cellular viability were observed after applying doxorubicin. The application of doxorubicin, particularly at higher concentrations, produced a noticeable decrease in alkaline phosphatase activity and Alizarin Red S staining. The present study indicated that application of doxorubicin with or without liposomes reduced the cellular viability and osteogenic differentiation. Among the different treatments, the doxorubicin-loaded cationic liposomes induced the strongest reduction
\end{abstract}

Correspondence to: Professor Jun-Beom Park, Department of Periodontics, College of Medicine, The Catholic University of Korea, 222 Banpo-daero, Seocho-gu, Seoul 06591, Republic of Korea

E-mail: jbassoonis@yahoo.co.kr

Professor Heebeom Koo, Department of Medical Lifescience, College of Medicine, The Catholic University of Korea, 222 Banpo-daero, Seocho-gu, Seoul 06591, Republic of Korea

E-mail: hbkoo@catholic.ac.kr

${ }^{*}$ Contributed equally

Key words: cell differentiation, doxorubicin, gingiva, liposomes, osteogenesis, stem cells in the cellular viability and osteogenic differentiation in the stem cell culture.

\section{Introduction}

Doxorubicin is an anthracycline-based topoisomerase II inhibitor and DNA-modifying agent that has exhibited remarkable anti-tumor effects against multiple cancer types, including ovarian, lung and endometrial cancers (1). Doxorubicin is known to act by intercalating into DNA and interfering with nucleic acid synthesis, which halts the cell cycle and inhibits DNA transcription (2). However, the clinical utility of doxorubicin as an anti-tumor drug is hampered by cardiotoxicity and drug resistance (3). Doxorubicin-mediated bone loss in cancer patients is produced by an interaction between oxidative stress and the induction of transforming growth factor- $\beta$ (TGF- $\beta$ ) (4). Doxorubicin treatment has also been indicated to increase the levels of circulating TGF- $\beta$ in murine pre-clinical models, and TGF- $\beta$ promoted osteolytic bone damage, leading to increased osteoclast-mediated resorption and suppression of osteoblast differentiation (4).

In numerous previous studies, liposomes have been used to deliver anti-cancer drugs, including doxorubicin, to local tumors (5). Liposomal doxorubicin along with conventional doxorubicin has potential risks of causing adverse events, including myelosuppression, cardiotoxicity, alopecia, nausea and vomiting (6). However, liposomal doxorubicin formulations are associated with lower reported odds ratios with regard to myelosuppression, cardiotoxicity and alopecia than conventional doxorubicin on its own (6). The effects of doxorubicin, particularly doxorubicin liposomes, on stem cells have remained to be fully elucidated (7). The aim of the present study was to evaluate the effects of anionic, cationic and neutral liposomes loaded with doxorubicin on the viability and osteogenic differentiation potential of human gingiva-derived stem cells in two-dimensional culture.

\section{Materials and methods}

Preparation of doxorubicin-loaded liposomes. The thin-lipid-film hydration method was used to prepare 
liposomes from the mixture. 1,2-dipalmitoyl-sn-glycero-3phosphocholine (DPPC, Echelon Biosciences, Salt Lake City, UT, USA) and cholesterol (Sigma-Aldrich; Merck KGaA, Darmstadt, Germany) at a weight ratio of 10:1 was used for the neutral liposome. For the cationic liposome, DPPC, 1,2-dipalmitoyl-3-trimethylammonium-propane (chloride salt, 16:0 TAP; Avanti Polar Lipids; Birmingham, AL, USA) and cholesterol were used at a weight ratio of 5:5:1 and for the anionic liposome, DPPC, 1,2-dipalmitoyl-sn-glycero-3-phosphoserine plus sodium salt (Echelon Biosciences) and cholesterol were used at a weight ratio of 5:5:1.

The lipids were dissolved in dichloromethane and the solvent was removed via evaporation under reduced pressure at $55^{\circ} \mathrm{C}$. Subsequently, a thin film of lipids was dispersed in distilled water (lipid concentration of $2.2 \mathrm{mg} / \mathrm{ml}$ ) with doxorubicin hydrochloride (LC Laboratories, Woburn, MA, USA) by sonication. Dialysis was then performed in order to remove the unloaded doxorubicin using distilled water for $1 \mathrm{~h}$. After disrupting the liposomes completely with a detergent solution (1\% Triton X-100; Samchun, Pyeongtaek-Si, South Korea), the amount of doxorubicin in the liposomes was evaluated based on the fluorescence of doxorubicin (490/570 nm).

Isolation of human gingiva-derived stem cells. The Institutional Review Board of Seoul St. Mary's Hospital (College of Medicine, Catholic University of Korea, Seoul, Republic of Korea) approved the present study (nos. KC17SNSI0606 and KC11SISI0348), and informed consent was obtained from the participants. Healthy patients visiting the Department of Periodontics of Seoul St. Mary's Hospital (College of Medicine, The Catholic University of Korea, Seoul, Republic of Korea) provided the gingiva tissue for the study. The epithelium of the gingiva was removed and the tissue was fragmented into 1-2 mm sections. The tissues were digested with a medium containing dispase $(1 \mathrm{mg} / \mathrm{ml}$; Sigma-Aldrich; Merck KGaA) and collagenase IV (2 mg/ml; Sigma-Aldrich; Merck KGaA) (8). Unattached cells were removed from the culture dish. The cells were then cultured in an incubator with $5 \% \mathrm{CO}_{2}$ and $95 \% \mathrm{O}_{2}$ at $37^{\circ} \mathrm{C}$, and the medium was changed every two to three days. For identification, $\sim 1.5 \times 10^{5}$ cells were incubated with specific fluorescein isothiocyanate-conjugated mouse monoclonal antibodies to human CD44 (11-0441-81; 1:200; BD Biosciences, Franklin Lakes, NJ, USA), CD73 (11-0739-42; 1:40; BD Biosciences), CD90 (11-0909-42; 1:40; BD Biosciences), CD14 (11-0149-42; 1:40; BD Biosciences) and CD34 (11-0349-42; 1:40; BD Biosciences) at room temperature for $30 \mathrm{~min}$. Flow cytometric analysis was performed using a flow cytometer (FACS Canto II; BD Biosciences,) and FACSDiva software (v8.0.1; BD Biosciences).

The 12 groups of the present study were as follows: i) Unloaded control group (D0); ii) doxorubicin, $1 \mu \mathrm{g} / \mathrm{ml}$ (D1); iii) doxorubicin, $10 \mu \mathrm{g} / \mathrm{ml}$ (D10); iv) unloaded anionic group (A0); v) anionic group loaded with $1 \mu \mathrm{g} / \mathrm{ml}$ doxorubicin (A1); vi) anionic group loaded with doxorubicin at $10 \mu \mathrm{g} / \mathrm{ml}$ (A10); vii) unloaded cationic group (C0); viii) cationic group loaded with doxorubicin at $1 \mu \mathrm{g} / \mathrm{ml}$ (C1); ix) cationic group loaded with doxorubicin at $10 \mu \mathrm{g} / \mathrm{ml}(\mathrm{C} 10) ; \mathrm{x})$ unloaded neutral group (N0); xi) neutral group loaded with doxorubicin at $1 \mu \mathrm{g} / \mathrm{ml}(\mathrm{N} 1)$; and xii) neutral group loaded with doxorubicin at $10 \mu \mathrm{g} / \mathrm{ml}(\mathrm{N} 10)(7,9)$.
Evaluation of cell morphology and determination of cell viability. The cells (within 10 passages) were seeded in 96-well plates at a density of $2.0 \times 10^{3}$ cells/well, and the cells were cultured in osteogenic medium. The osteogenic medium consisted of $\alpha$-minimal essential medium (Gibco; Thermo Fisher Scientific, Inc., Waltham, MA, USA) containing 15\% fetal bovine serum (Gibco; Thermo Fisher Scientific, Inc.), $100 \mathrm{U} / \mathrm{ml}$ penicillin, $100 \mu \mathrm{g} / \mathrm{ml}$ streptomycin (Sigma-Aldrich; Merck KGaA), 200 mM L-glutamine (Sigma-Aldrich; Merck $\mathrm{KGaA}$ ), $10 \mathrm{mM}$ ascorbic acid 2-phosphate (Sigma-Aldrich; Merck KGaA), $38 \mu \mathrm{g} / \mathrm{ml}$ dexamethasone and $2 \mathrm{mg} / \mathrm{ml}$ glycerophosphate disodium salt hydrate. The morphology of the cells was observed under an inverted microscope (Leica DM IRM, Leica Microsystems, Wetzlar, Germany) on days 1,3 and 7 .

On days 1,3 and 7, a cell viability analysis of the stem cell spheroids cultured in osteogenic medium was performed. Cell Counting Kit-8 (CCK-8) stain (Dojindo, Kumamoto, Japan) was added to the cultures and the stem cells were incubated for $1 \mathrm{~h}$ at $37^{\circ} \mathrm{C}$. Viable cells were identified by CCK-8 staining, which relies on the ability of mitochondrial dehydrogenases to oxidize the dye into a colored formazan product. A microplate reader (BioTek, Winooski, VT, USA) was used to measure the spectrophotometric absorbance of the samples at $450 \mathrm{~nm}$.

Alkaline phosphatase activity assay. The stem cells were seeded on 24-well plates at a density of $2.0 \times 10^{4}$ cells/well and the cells were cultured in the osteogenic medium. On days 1 , 5 and 7 , alkaline phosphatase activity assays were performed using a commercially available kit (K412-500; BioVision, Inc., Milpitas, CA, USA). The cells were re-suspended in an assay buffer, sonicated and centrifuged to remove any insoluble material. The supernatant was mixed with p-nitrophenyl phosphate substrate and incubated at $25^{\circ} \mathrm{C}$ for $60 \mathrm{~min}$. The optical density of the resultant p-nitrophenol was determined spectrophotometrically at $405 \mathrm{~nm}$.

Alizarin Red S staining. Alizarin Red S staining was performed on days 7 and 14. In brief, the cells were washed twice with PBS, fixed with $4 \%$ paraformaldehyde at room temperature and rinsed twice with deionized water. The cultures were then stained with Alizarin Red S for 30 min at room temperature. To remove non-specifically bound dye, the cultures were washed three times with deionized water. The morphology was evaluated using an inverted microscope (Leica DM IRM; Leica Microsystems).

Statistical analysis. The results are expressed as the mean \pm standard deviation of the experiments. Normality of the data was assessed with a Shapiro-Wilk test, and one-way analysis of variance followed by Tukey's post-hoc test was performed to determine the differences between the groups using SPSS 12 for Windows (SPSS Inc., Chicago, IL, USA). $\mathrm{P}<0.05$ was considered to indicate a statistically significant difference.

\section{Results}

Effects of doxorubicin-loaded liposomes on cell morphology and viability. The expression of the CD44, CD73, CD90, 


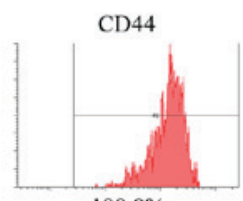

$100.0 \%$

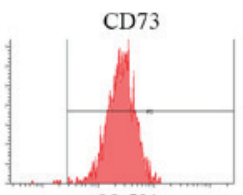

$99.5 \%$
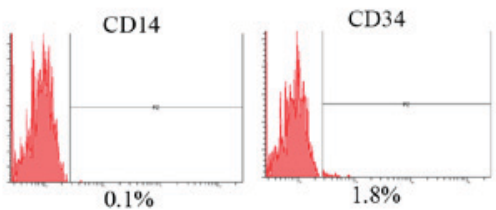

Figure 1. Evaluation of stem cell surface marker expression using CD44 CD73, CD90, CD14 and CD34. The percentages of CD44 ${ }^{+}, \mathrm{CD}_{3}{ }^{+}, \mathrm{CD} 0^{+}$, $\mathrm{CD}_{14}{ }^{+}$and $\mathrm{CD} 34^{+}$cells were $100,99.5,99.9,0.1$ and $1.8 \%$, respectively.

CD14 and CD34 surface markers was assessed (Fig. 1). The percentages of $\mathrm{CD} 44^{+}, \mathrm{CD}^{+} 3^{+}, \mathrm{CD} 90^{+}, \mathrm{CD} 14^{+}$and $\mathrm{CD} 34^{+}$cells were $100,99.5,99.9,0.1$ and $1.8 \%$, respectively. Therefore, the cells were positive for stem cell surface markers. The control group D0 exhibited a normal fibroblast morphology on day 1 (Fig. 2). No significant morphological changes of stem cells cultured in the osteogenic media were observed after the addition of anionic, cationic or neutral doxorubicin (A0, C0 or N0). No noticeable changes were observed with the addition of doxorubicin at day 1 (D1 or D10). Similar trends were observed in the anionic and cationic liposomes loaded with doxorubicin at day 1 . However, in the cells treated with the cationic liposome, noticeable changes in morphology at the highest concentration (C10) were noted at day 1. In general, the morphologies of the stem cells at days 3 were similar to those at day 1 (Fig. 3). In the cationic liposome groups, the low concentration of doxorubicin (C1) produced cells with rounder and more amorphous shapes. More pronounced changes in the morphology of the stem cells were seen in the cationic doxorubicin-loaded groups (C1 and C10) at day 7 (Fig. 4).

The results of the CCK- 8 assay performed on days 1, 3, and 7 are presented in Fig. 5. Application of doxorubicin at a high concentration on day 1 produced significant differences in cell viability when compared with that in the D0 group at day 1 .

Alkaline phosphatase activity. The alkaline phosphatase activity on days 1, 5 and 7 in the cells treated with doxorubicin is presented in Fig. 6. The alkaline phosphatase activity increased with longer incubation times. Noticeable decreases in alkaline phosphatase activity were observed in the D1, D10, $\mathrm{A} 0, \mathrm{~A} 1, \mathrm{~A} 10, \mathrm{C} 0, \mathrm{C} 1, \mathrm{~N} 0, \mathrm{~N} 1$ and N10 groups at day 1.

Alizarin Red S staining. The amount of mineralized extracellular deposits was evaluated in the control groups (D0, A0, C0 and N0) using Alizarin Red S staining on days 7 and 14 (Figs. 7 and 8). Mineralized extracellular deposits were noted to in each group and intensity differed among the groups. An increase in mineralized deposits was noted on day 14 as compared to day 7. The application of doxorubicin reduced the Alizarin Red S staining in the doxorubicin-only group and the different liposome groups. The morphology of the

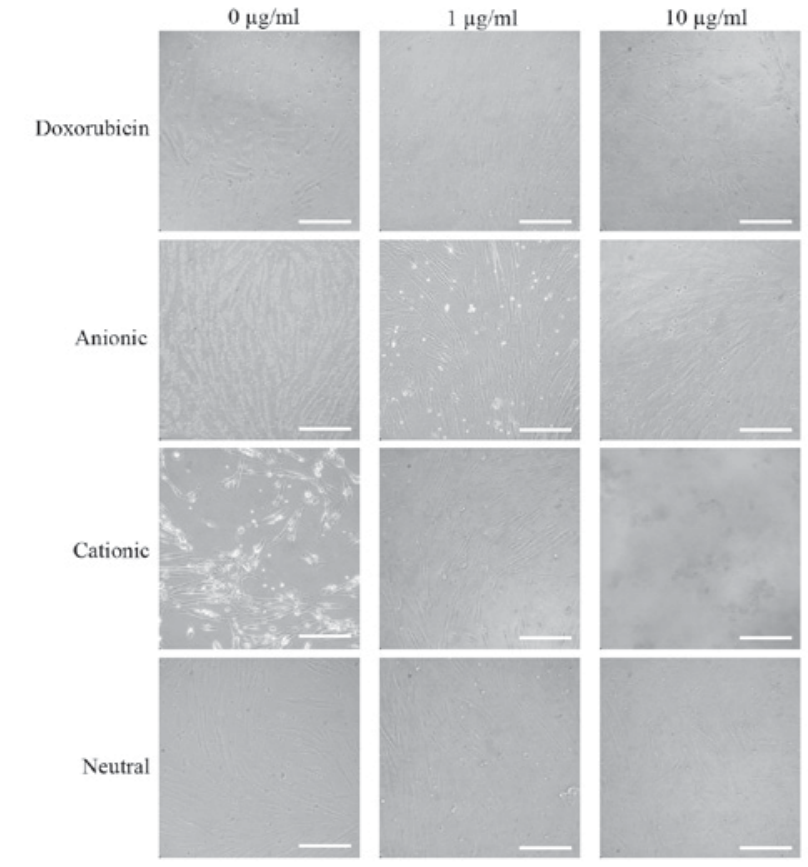

Figure 2. Morphology of gingiva-derived stem cells cultured in osteogenic media for 1 day (original magnification, x200; scale bar, $200 \mu \mathrm{m}$ ).

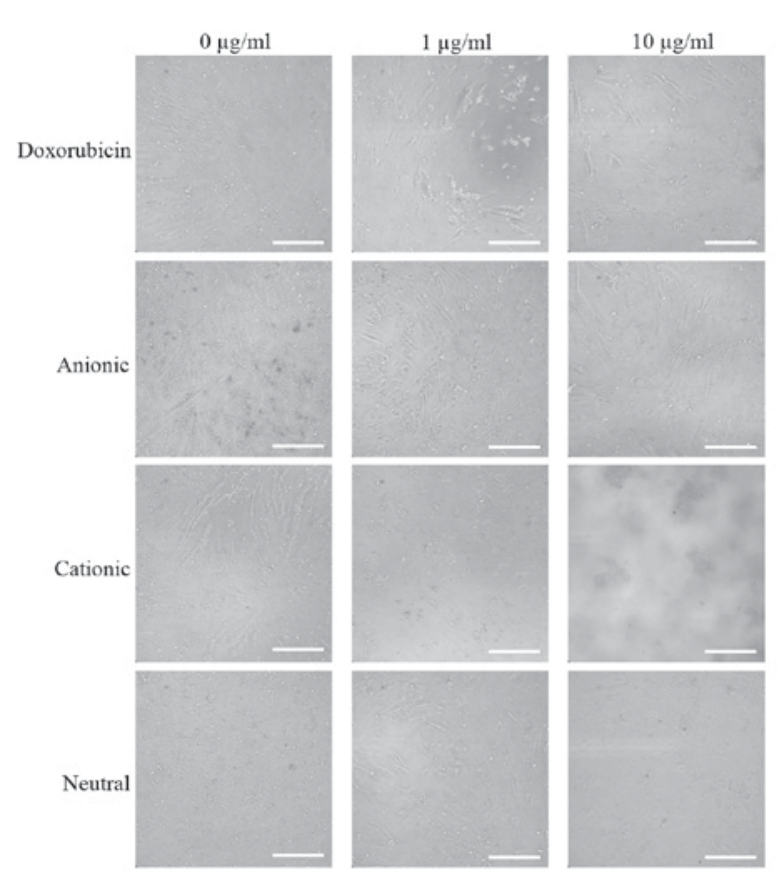

Figure 3. Morphology of gingiva-derived stem cells cultured in osteogenic media for 3 days (original magnification, x200; scale bar, $200 \mu \mathrm{m}$ ).

cationic doxorubicin-loaded groups was affected the most among the anionic, cationic and neutral doxorubicin-loaded liposome groups. The relative values at day 7 for D0, D1, D10, $\mathrm{A} 0, \mathrm{~A} 1, \mathrm{~A} 10, \mathrm{C} 0, \mathrm{C} 1, \mathrm{C} 10, \mathrm{~N} 0, \mathrm{~N} 1$ and $\mathrm{N} 10$ are presented in Fig. 9. Significant decreases in Alizarin Red S staining were observed in the D1, D10, A0, A1, A10, N1 and N10 groups at day 14. Notable morphological changes in the number of cells were observed in $\mathrm{C} 1$ and $\mathrm{C} 10$ groups at day 14 . 


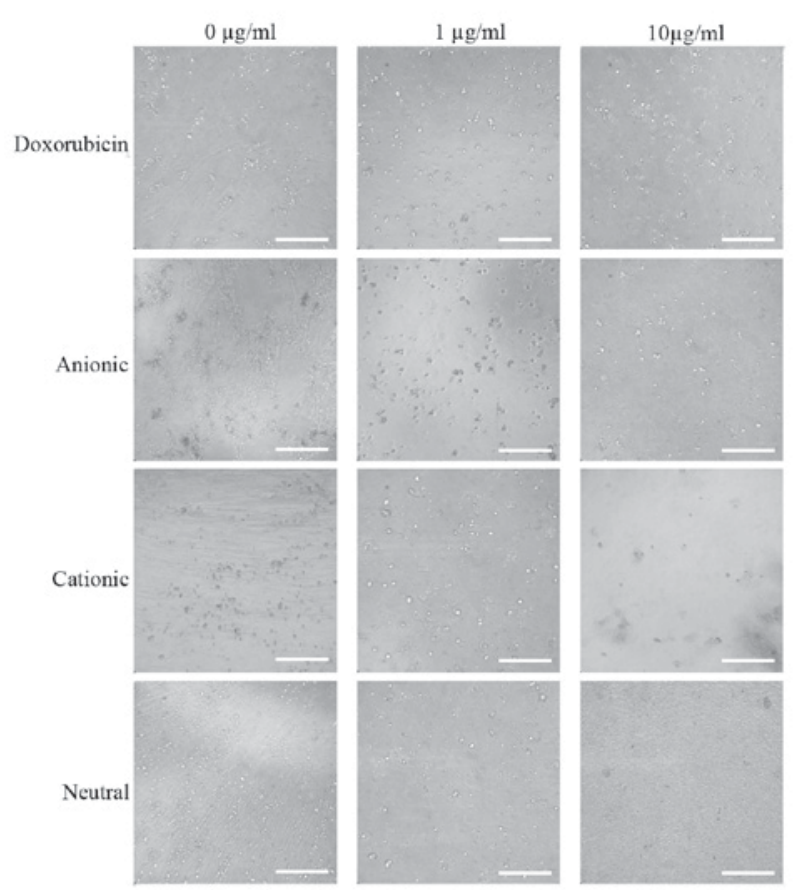

Figure 4. Morphology of gingiva-derived stem cells cultured in osteogenic media on day 7 (original magnification, x200; scale bar, $200 \mu \mathrm{m}$ ).

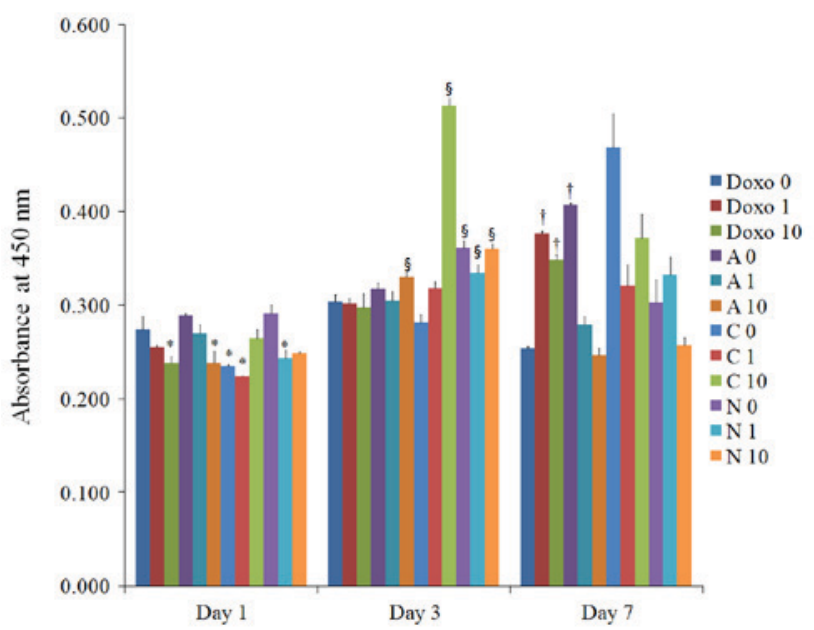

Figure 5. Cellular viability on days 1,3 , and 7 determined using a Cell Counting Kit- 8 . ${ }^{*} \mathrm{P}<0.05$ vs. doxorubicin $0 \mu \mathrm{g} / \mathrm{ml}$ group on day $1 ;{ }^{\circledR} \mathrm{P}<0.05$ vs. doxorubicin $0 \mu \mathrm{g} / \mathrm{ml}$ group on day $3 ;{ }^{\dagger} \mathrm{P}<0.05 \mathrm{vs}$. doxorubicin $0 \mu \mathrm{g} / \mathrm{ml}$ group on day 7. A 1 , anionic liposome $+1 \mu \mathrm{g} / \mathrm{ml}$ doxorubicin; $\mathrm{C}$, cationic liposome; $\mathrm{N}$, neutral liposome; Doxo, doxorubicin alone.

\section{Discussion}

In the present study, the effects of liposomes of different ionic types loaded with doxorubicin on the viability and osteogenic differentiation potential of gingiva-derived stem cells in two-dimensional culture were evaluated. The results indicated that application of doxorubicin with or without liposomes reduced the cellular viability and osteogenic differentiation. The doxorubicin-loaded cationic liposomes induced the strongest reduction in the cell viability and osteogenic differentiation in the cultured stem cells.

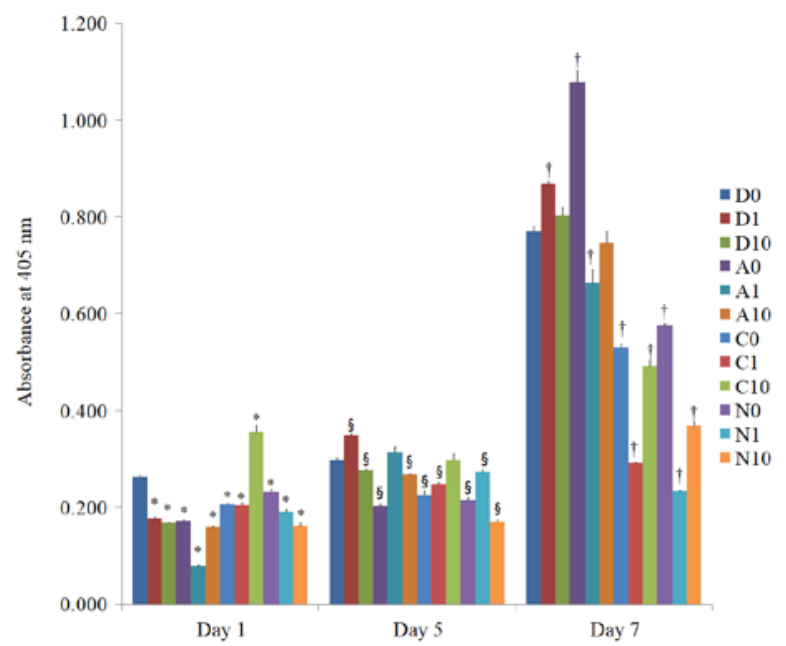

Figure 6. Alkaline phosphatase activity on days 1,5 and 7 . $^{*} \mathrm{P}<0.05$ vs. doxorubicin $0 \mu \mathrm{g} / \mathrm{ml}$ group on day $1 ;{ }^{\S} \mathrm{P}<0.05 \mathrm{vs}$. doxorubicin $0 \mu \mathrm{g} / \mathrm{ml}$ group on day $3 ;{ }^{\dagger} \mathrm{P}<0.05 \mathrm{vs}$. doxorubicin $0 \mu \mathrm{g} / \mathrm{ml}$ group on day 7 . A 1 , anionic liposome $+1 \mu \mathrm{g} / \mathrm{ml}$ doxorubicin; $\mathrm{C}$, cationic liposome; $\mathrm{N}$, neutral liposome; Doxo, doxorubicin alone.
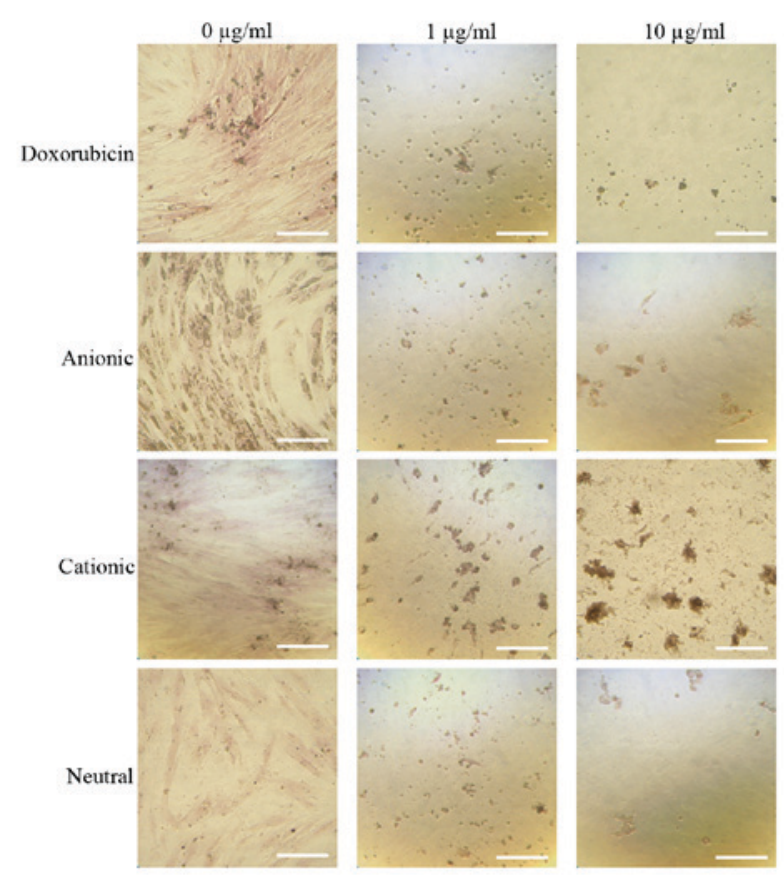

Figure 7. Results of the Alizarin Red S staining on day 7 (original magnification, x200; scale bar, $200 \mu \mathrm{m}$ ).

Liposomes are nanoparticle lipid vesicles that are composed of continuous bilayers of phospholipids surrounding an aqueous phase; they have been investigated as drug-delivery systems for improved targeted delivery of therapeutic agents (10). Doxorubicin-loaded liposomes have been demonstrated to enhance the oral bioavailability of drugs by modulation of their physicochemical characteristics (11). In a previous study, doxorubicin-loaded polyethylene glycosylated liposomes were accumulated and retained in the targeted site, and it was reported that such liposome complexes increased the therapeutic efficacy of drugs, thus providing a 


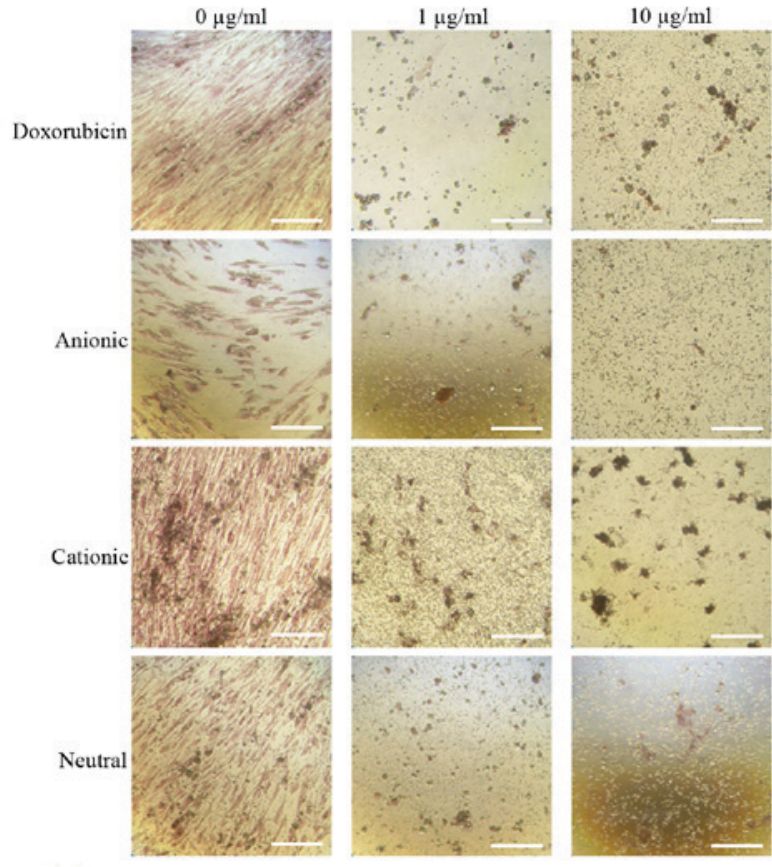

Figure 8. Results of the Alizarin Red S staining on day 14 (original magnification, x200; scale bar, $200 \mu \mathrm{m}$ ).

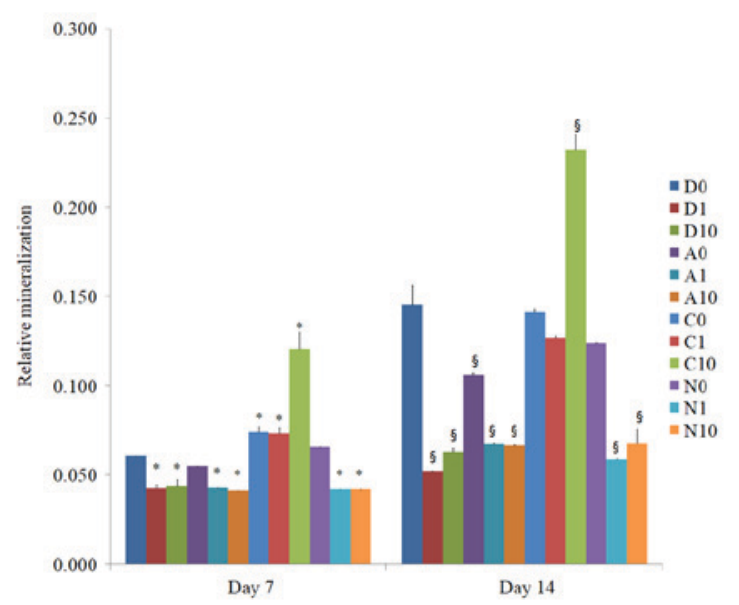

Figure 9. Qualitative results of the Alizarin Red S staining. "P $<0.05$ vs. doxorubicin $0 \mu \mathrm{g} / \mathrm{ml}$ group on day $7 ;{ }^{\circledR} \mathrm{P}<0.05$ vs. doxorubicin $0 \mu \mathrm{g} / \mathrm{ml}$ group on day 14. A 1 , anionic liposome $+1 \mu \mathrm{g} / \mathrm{ml}$ doxorubicin; $\mathrm{C}$, cationic liposome; $\mathrm{N}$, neutral liposome; Doxo, doxorubicin alone.

promising therapeutic approach (10). Ion-pairing technology using a doxorubicin-cholesteryl hemisuccinate ion-pair complex based on the conventional thin-film dispersion method produced high drug loading and a high entrapment efficiency (12). Co-liposomes prepared with gemini along with a natural zwitterionic lipid, phospholipid and cholesterol produced H-responsive co-liposomes, which were able to transport doxorubicin efficiently across doxorubicin-resistant cancer cells (13).

In the present study, liposomes of different ionic types were loaded with doxorubicin. The doxorubicin-loaded cationic liposomes had the greatest effects on cultured stem cells and their osteogenic differentiation. The differences in the surface charge may have affected the uptake of doxorubicin by the stem cells (14). Doxorubicin-induced toxicity negatively impacts the clinical utility and outcomes (15). The composition of lipids in liposomes may determine the drug encapsulation efficacy and release kinetics of doxorubicin, which may impact the clinical toxicity (16). Liposomal co-delivered oleanolic acid has been reported to attenuate doxorubicin-induced multi-organ toxicity (15). Another previous study suggested that miR-1, -21 and -145 may be involved in the toxicity induced by doxorubicin, which may be considered as targets for reducing its toxicity (17).

In the present study, the effects of liposomes loaded of different ionic types loaded with doxorubicin on the cellular viability and osteogenic differentiation potential of stem cells in two-dimensional culture were evaluated. The results indicated that application of doxorubicin reduced the cellular viability and osteogenic differentiation with or without liposomes. The doxorubicin-loaded cationic liposomes induced the strongest reduction in the cell viability and osteogenic differentiation in the cultured stem cells.

\section{Acknowledgements}

Not applicable.

\section{Funding}

This study was partly supported by the Research Fund of Seoul St. Mary's Hospital, The Catholic University of Korea (Seoul, Korea) in 2017. This work was further supported by the Basic Science Research Program of the Ministry of Education (grant no. 2016R1C1B3013951) through the National Research Foundation of Korea and the financial support of the Catholic Medical Center Research Foundation in the program year of 2016. This study was partly supported by the Basic Science Research Program through the National Research Foundation of Korea (NRF) funded by the Ministry of Science, Information and Communication Technology \& Future Planning (grant no. NRF-2017R1A1A1A05001307).

\section{Availability of data and materials}

All data generated or analyzed during the present study are included in the published article.

\section{Authors' contributions}

HL, JS, GY, HK and JP designed the study, performed the experiments, were responsible for data collection and analysis, and participated in drafting the manuscript. All the authors read and approved the final version of the manuscript.

\section{Ethical approval and consent to participate}

The Institutional Review Board of Seoul St. Mary's Hospital, College of Medicine, Catholic University of Korea (Seoul, Korea) approved this study (nos. KC17SNSI0606 and KC11SISI0348). Informed consent was obtained from all of the participants. 


\section{Patient consent for publication}

Not applicable.

\section{Competing interests}

The authors declare that they have no competing interests.

\section{References}

1. Ruttala HB, Ramasamy T, Gupta B, Choi HG, Yong CS and Kim JO: Multiple polysaccharide-drug complex-loaded liposomes: A unique strategy in drug loading and cancer targeting. Carbohydr Polym 173: 57-66, 2017.

2. Bagnyukova TV, Serebriiskii IG, Zhou Y, Hopper-Borge EA, Golemis EA and Astsaturov I: Chemotherapy and signaling: How can targeted therapies supercharge cytotoxic agents? Cancer Biol Ther 10: 839-853, 2010.

3. Zhang Y, Zhai M, Chen Z, Han X, Yu F, Li Z, Xie X, Han C, Yu L, Yang Y and Mei X: Dual-modified liposome codelivery of doxorubicin and vincristine improve targeting and therapeutic efficacy of glioma. Drug Deliv 24: 1045-1055, 2017.

4. Rana T, Chakrabarti A, Freeman $M$ and Biswas $S$ : Doxorubicin-mediated bone loss in breast cancer bone metastases is driven by an interplay between oxidative stress and induction of TGFbeta. PLoS One 8: e78043, 2013.

5. Affram K, Udofot O, Singh M, Krishnan S, Reams R, Rosenberg J and Agyare E: Smart thermosensitive liposomes for effective solid tumor therapy and in vivo imaging. PLoS One 12: e0185116, 2017.

6. Fukuda A, Tahara K, Hane Y, Matsui T, Sasaoka S, Hatahira H, Motooka Y, Hasegawa S, Naganuma M, Abe J, et al: Comparison of the adverse event profiles of conventional and liposomal formulations of doxorubicin using the FDA adverse event reporting system. PLoS One 12: e0185654, 2017.

7. Lee H, Son J, Na CB, Yi G, Koo H and Park JB: The effects of doxorubicin-loaded liposomes on viability, stem cell surface marker expression and secretion of vascular endothelial growth factor of three-dimensional stem cell spheroids. Exp Ther Med 15: 4950-4960, 2018.

8. Jin SH, Lee JE, Yun JH, Kim I, Ko Y and Park JB: Isolation and characterization of human mesenchymal stem cells from gingival connective tissue. J Periodontal Res 50: 461-467, 2015.
9. Contrera JF, Matthews EJ, Kruhlak NL and Benz RD: Estimating the safe starting dose in phase I clinical trials and no observed effect level based on QSAR modeling of the human maximum recommended daily dose. Regul Toxicol Pharmacol 40: 185-206, 2004.

10. Niu H, Xu M, Li S, Chen J, Luo J, Zhao X, Gao C and Li X High-performance liquid chromatography (HPLC) quantification of liposome-delivered doxorubicin in arthritic joints of collagen-induced arthritis rats. Med Sci Monit Basic Res 23: 150-158, 2017.

11. Daeihamed M, Haeri A, Ostad SN, Akhlaghi MF and Dadashzadeh S: Doxorubicin-loaded liposomes: Enhancing the oral bioavailability by modulation of physicochemical characteristics. Nanomedicine (Lond) 12: 1187-1202, 2017.

12. Xu H, Zhang L, Li L, Liu Y, Chao Y, Liu X, Jin Z, Chen Y, Tang X, He H, et al: Membrane-loaded doxorubicin liposomes based on ion-pairing technology with high drug loading and pH-responsive property. AAPS PharmSciTech 18: 2120-2130, 2017.

13. Moitra P, Kumar K, Sarkar S, Kondaiah P, Duan W and Bhattacharya S: New pH-responsive gemini lipid derived co-liposomes for efficacious doxorubicin delivery to drug resistant cancer cells. Chem Commun (Camb) 53: 8184-8187, 2017.

14. Lee S, Lee SY, Park S, Ryu JH, Na JH, Koo H, Lee KE, Jeon H, Kwon IC, Kim K and Jeong SY: In vivo NIRF imaging of tumor targetability of nanosized liposomes in tumor-bearing mice. Macromol Biosci 12: 849-856, 2012.

15. Sarfraz M, Afzal A, Raza SM, Bashir S, Madni A, Khan MW, Ma X and Xiang G: Liposomal co-delivered oleanolic acid attenuates doxorubicin-induced multi-organ toxicity in hepatocellular carcinoma. Oncotarget 8: 47136-47153, 2017.

16. Sreekanth V, Medatwal N, Pal S, Kumar S, Sengupta S and Bajaj A: Molecular self-assembly of bile acid-phospholipids controls the delivery of doxorubicin and mice survivability. Mol Pharm 14: 2649-2659, 2017.

17. Razavi-Azarkhiavi K, Jaafari MR, Abnous K, Razavi BM, Jafarian AH, Hassani FV, Shirani K and Karimi G: The cardiotoxic mechanism of doxorubicin (DOX) and pegylated liposomal DOX in mice bearing C-26 colon carcinoma: A study focused on microRNA role for toxicity assessment of new formulations. Pharm Res 34: 1849-1856, 2017. International (CC BY-NC-ND 4.0) License. 